Check for updates

Cite this: J. Mater. Chem. A, 2018, 6 , 6847

\section{Highly permeable CHA membranes prepared by fluoride synthesis for efficient $\mathrm{CO}_{2} / \mathrm{CH}_{4}$ separation}

\begin{abstract}
Liang Yu, (D)* Allan Holmgren, Ming Zhou and Jonas Hedlund
All-silica CHA nanocrystals, much smaller $(20-200 \mathrm{~nm})$ than previously reported, were prepared by an improved method developed in the present work. The nanocrystals are prepared by adding milled crystals to a fluoride synthesis mixture and we observed that much smaller crystals are obtained by adding a much higher fraction of milled crystals. In the next step, CHA membranes with a thickness of ca. $1.3 \mu \mathrm{m}$ were prepared by hydrothermal treatment of a monolayer of nanocrystals supported on porous graded alumina discs in a fluoride synthesis gel. Finally, the membranes were calcined at $480{ }^{\circ} \mathrm{C}$. The highest measured single gas $\mathrm{CO}_{2}$ permeance was $172 \times 10^{-7} \mathrm{~mol} \mathrm{~m}{ }^{-2} \mathrm{~s}^{-1} \mathrm{~Pa}^{-1}$ at room temperature. The highly permeable membranes were evaluated for separation of $\mathrm{CO}_{2}$ from an equimolar mixture with $\mathrm{CH}_{4}$ at varying temperatures. The highest observed $\mathrm{CO}_{2}$ mixture permeance was $84 \times$ $10^{-7} \mathrm{~mol} \mathrm{~m} \mathrm{~m}^{-2} \mathrm{~s}^{-1} \mathrm{~Pa}^{-1}$ at $276 \mathrm{~K}$ with a separation selectivity of 47 at 9 bar feed pressure and atmospheric permeate pressure. At room temperature, the $\mathrm{CO}_{2}$ mixture permeance was also as high as $78 \times 10^{-7} \mathrm{~mol} \mathrm{~m}^{-2} \mathrm{~s}^{-1} \mathrm{~Pa}^{-1}$ with a separation selectivity of 32. To the best of our knowledge, these $\mathrm{CO}_{2}$ permeances are by far the highest reported for $\mathrm{CHA}$ membranes, while the selectivity is similar to that reported previously at comparable test conditions.
\end{abstract}

Received 5th February 2018 Accepted 26th March 2018

DOI: $10.1039 / \mathrm{c} 8 \mathrm{ta0} 1240 \mathrm{~g}$

rsc.li/materials-a costs. Zeolite membranes have been considered promising alternatives to polymeric membranes due to much higher chemical stability. ${ }^{4}$ In addition, zeolite membranes are porous, which may allow for much higher permeances compared to dense polymeric membranes. In turn, a much smaller membrane area and fewer membrane modules would be needed for a given separation task. We have shown that highly permeable zeolite membranes are economically competitive with polymeric membranes for $\mathrm{CO}_{2}$ separation. ${ }^{5}$

Several types of zeolite membrane have been investigated for $\mathrm{CO}_{2}$ separation from $\mathrm{CH}_{4}$, such as MFI, ${ }^{6}$ zeolite T, ${ }^{7} \mathrm{DDR},{ }^{8} \mathrm{SAPO}-$ $34,{ }^{9}$ and AlPO-18 (ref. 10) etc. Particularly interesting for this separation is CHA (also known as SSZ-13) zeolite. The unit cell is rhombohedral with a 3-dimensional pore structure and intersecting channels running in the $\langle 100\rangle$ family of directions. The window diameter is $0.37 \mathrm{~nm} \times 0.37 \mathrm{~nm},{ }^{11}$ i.e. in-between the kinetic diameters 0.33 and $0.38 \mathrm{~nm}$ of $\mathrm{CO}_{2}$ and $\mathrm{CH}_{4}$, respectively. SSZ-13 and all-silica CHA zeolites displayed $\mathrm{CO}_{2} / \mathrm{CH}_{4}$ adsorption selectivity of up to 4.1 at room temperature. ${ }^{12}$ The pore size and its selective adsorption properties, makes this zeolite promising as a membrane and simulations have shown that the $\mathrm{CO}_{2} / \mathrm{CH}_{4}$ permeation selectivity could be around 100 at room temperature. ${ }^{13}$ Previously, SSZ-13 crystals $^{14}$ and membranes ${ }^{15,16}$ were synthesized using $N, N, N$-trimethyl-1-adamant ammonium hydroxide (TMAdaOH) as the structure-directing agent (SDA). A SSZ-13 membrane with a $\mathrm{CO}_{2} / \mathrm{CH}_{4}$ separation selectivity of 13 and a $\mathrm{CO}_{2}$ permeance of $1.7 \times 10^{-7} \mathrm{~mol} \mathrm{~m}^{-2} \mathrm{~s}^{-1} \mathrm{~Pa}^{-1}$ has been reported. ${ }^{16}$ Steam-stable high-silica $\mathrm{CHA}$ membranes with a $\mathrm{CO}_{2} /$ 
$\mathrm{CH}_{4}$ selectivity as high as 300 and a $\mathrm{CO}_{2}$ permeance of $2.0 \times$ $10^{-7} \mathrm{~mol} \mathrm{~m}{ }^{-2} \mathrm{~s}^{-1} \mathrm{~Pa}^{-1}$ have also been reported. ${ }^{17}$ Another example is a high-silica SSZ-13 CHA membrane with a $\mathrm{CO}_{2}$ permeance of $3.0 \times 10^{-7} \mathrm{~mol} \mathrm{~m}^{-2} \mathrm{~s}^{-1} \mathrm{~Pa}^{-1}$ and a separation selectivity of 42 for equimolar $\mathrm{CO}_{2} / \mathrm{CH}_{4}$ mixtures. ${ }^{18}$

Fluoride-mediated synthesis of zeolite membranes has been reported to improve the stability and reduce membrane defects. ${ }^{19}$ In aluminium-free fluoride media, the concentration of lattice defects should also be low as indicated by research of Hensen et al. ${ }^{\mathbf{2 0}}$ However, the precursors, i.e. CHA seeds, utilized so far were too large to admit the growth of a thin intergrown membrane in fluoride media.

To prepare thin and aluminium-free CHA membranes entirely in fluoride media, Si-CHA zeolite nanocrystals, which are also prepared from fluoride media, are needed. The synthesis of such nanoparticles is a challenge due to the inhomogeneous nature of the fluoride synthesis gel. ${ }^{17}$ However, in the present work, we successfully synthesised Si-CHA zeolite nanocrystals in fluoride media for the first time. In the next step, these crystals were used as seeds and enabled growth of very thin and highly permeable membranes by hydrothermal treatment in a fluoride synthesis gel.

\section{Experimental}

\section{Preparation of Si-CHA nanocrystals}

In the first step, CHA microcrystals were prepared by mixing distilled water, colloidal silica (Ludox AS-40), $N, N, N$-trimethyl-1adamant ammonium hydroxide (TMAdaOH 25\%, SACHEM, Inc.) and hydrofluoric acid (48\%) in a PTFE bottle. After stirring overnight, part of the water was removed by freeze-drying to obtain a synthesis gel with a molar composition of $1.0 \mathrm{SiO}_{2}$ : 1.4TMAdaF : $9.4 \mathrm{H}_{2} \mathrm{O}$. Hydrothermal synthesis was then carried out at $175{ }^{\circ} \mathrm{C}$ for 1 day. Pure CHA microcrystals were obtained after centrifuging and washing by distilled water six times.

The CHA microcrystals were milled in DDI water using $3 \mathrm{~mm}$ glass beads in a glass bottle by shaking at $500 \mathrm{rpm}$ for 1 day. In the next step, CHA nanocrystals were prepared using essentially the same procedure as for the preparation of Si-CHA microcrystals, except that a certain amount of milled CHA microcrystals dispersed in water was added to the synthesis gel before freezedrying. The mass ratio between milled CHA microcrystals and $\mathrm{SiO}_{2}$ in the gel was 1 :3.9. After freeze-drying, the final molar composition of the gel used for growth of nanocrystals (apart from the milled CHA microcrystals) was the same as for the gel used for preparation of CHA microcrystals. Finally, CHA nanocrystals were obtained by hydrothermal treatment of the gel at $160{ }^{\circ} \mathrm{C}$ for 1 day. After repeated centrifugation and re-dispersion in water six times, a $1 \mathrm{wt} \%$ colloidal dispersion of CHA nanocrystals was prepared and the $\mathrm{pH}$ was adjusted to 10 by ammonia.

\section{Membrane preparation and characterisation}

The membranes were prepared as described in detail in a pending patent application. ${ }^{21}$ Porous graded $\alpha$-alumina discs (Fraunhofer IKTS, Germany) with a diameter of $25 \mathrm{~mm}$ were used as supports. The top layer of the disc was $30 \mu \mathrm{m}$ thick with a pore size of $100 \mathrm{~nm}$, and the base layer was $3 \mathrm{~mm}$ thick with a pore size of $3 \mu \mathrm{m}$. Before seeding, the colloidal dispersion of CHA nanocrystals was filtered through a $0.8 \mu \mathrm{m}$ filter. The synthesis gel used for growth of the seed layer to a membrane was prepared in the same way and had the same molar composition as the gel used for the preparation of CHA microcrystals but the gel was aged at $60{ }^{\circ} \mathrm{C}$ for $6 \mathrm{~h}$ prior to use. The aged gel was poured into a PTFE-lined autoclave $(30 \mathrm{ml})$ in which the seeded $\alpha$-alumina support was placed on the bottom of the autoclave with the seeded side down. Film growth was carried out at $160{ }^{\circ} \mathrm{C}$ for $18 \mathrm{~h}$. After synthesis, the membrane was rinsed in a $0.1 \mathrm{M}$ aqueous $\mathrm{NH}_{3}$ solution and then dried at $80^{\circ} \mathrm{C}$ overnight. Finally, the organic template in the membranes was removed by calcination at $480{ }^{\circ} \mathrm{C}$ for $16 \mathrm{~h}$ at a heating rate of $0.2{ }^{\circ} \mathrm{C} \min ^{-1}$ and a cooling rate of $0.3{ }^{\circ} \mathrm{C} \min ^{-1}$.

The phase of the zeolite crystals and films was determined by X-ray diffraction (XRD) using a PANalytical Empyrean diffractometer equipped with a Cu LFF HR X-ray tube and a PIXcel ${ }^{3 \mathrm{D}}$ detector. During the measurement, the irradiated length was fixed to $1 \mathrm{~mm}$ by a variable divergence slit. The morphology and microstructure of the crystals and membranes was investigated by scanning electron microscopy (SEM), using an FEI Magellan 400 field emission instrument. The samples were not coated prior to analysis.

\section{Single gas and mixed-gas separation experiments}

The membranes were mounted in stainless steel cells using graphite gaskets (Eriks, the Netherlands) for sealing. To evaluate the quality of the as-synthesized membranes, single gas He permeation experiment was carried out before calcination using 6 bar (absolute) feed pressure and atmospheric permeate pressure, i.e. a $\Delta P$ of 5 bar. Single gas permeation experiments of $\mathrm{He}$ and $\mathrm{CO}_{2}$ at room temperature were carried out using 1.8 bar (absolute) feed pressure and atmospheric permeate pressure, i.e. a $\Delta P$ of 0.8 bar directly after calcination. Single gas $\mathrm{CO}_{2}$ permeation experiments at room temperature were also carried out at different feed pressures and atmospheric permeate pressure after calcination.

Before separation experiments, the membranes were dried in a flow of helium at $300{ }^{\circ} \mathrm{C}$ for $6 \mathrm{~h}$ with a heating rate of $1{ }^{\circ} \mathrm{C} \min ^{-1}$ and then allowed to cool naturally. For permeation experiments at sub-ambient temperatures, the cell was placed in a thermostated silicone oil bath. Permeation experiments were performed in a continuous flow mode using an equimolar $\mathrm{CO}_{2} / \mathrm{CH}_{4}$ gas mixture that was fed to the membrane using mass flow controllers. The retentate pressure was controlled by a back pressure regulator and the pressure on both sides of the membrane was monitored by pressure gauges. The feed pressure was 9 bar (absolute pressure) and the volumetric flow rate

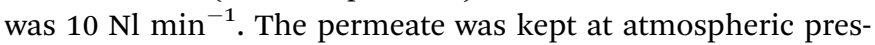
sure and no sweep gas was used. Consequently, the pressure ratio, $\varphi=P_{\text {Feed }} / P_{\text {Perm }}$, was 9 . The permeate flow was measured using a bubble flow meter, and the composition of feed and permeate streams was analysed online using a GC (490 Micro GC, Agilent). 


\section{Results and discussion}

Fig. 1a shows a SEM image of as-synthesised CHA microcrystals. The crystals were $c a .20 \mu \mathrm{m}$ in size, with a well-defined pseudocube habit, as reported previously for CHA crystals prepared in fluoride media. ${ }^{20}$ The XRD pattern for these crystals is shown in Fig. 2. The detected reflections were typical of the CHA framework, ${ }^{11}$ no other phase was present as evident from comparison with the reference pattern of K-exchanged aluminosilicate CHA indicated by bars. ${ }^{22}$ The shift of the reflections can be assigned to the aluminium free form of the zeolite crystals prepared in the present work as compared to the reference zeolite with an $\mathrm{Si} / \mathrm{Al}$ ratio of $2 .{ }^{23}$ Fig. $1 \mathrm{~b}$ shows a SEM image of the prepared Si-CHA nanocrystals. The size of the
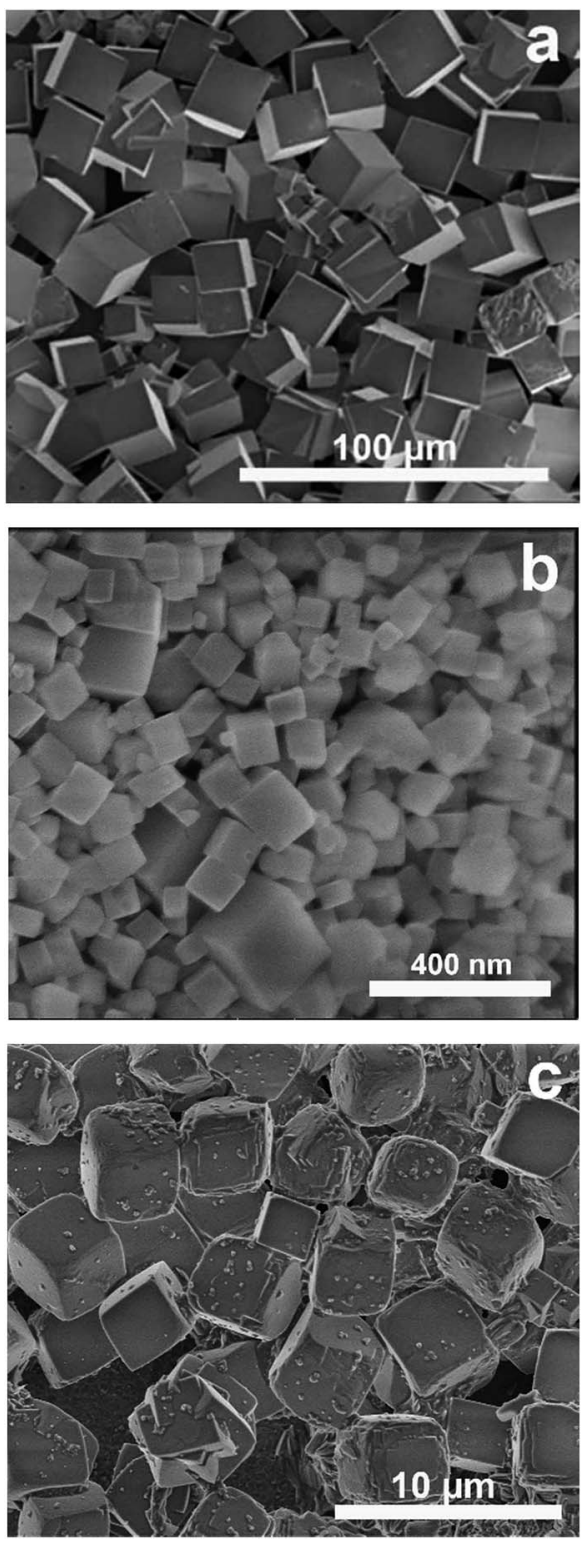

Fig. 1 SEM images of CHA microcrystals (a), nanocrystals (b) and the microcrystals (c) collected from the bottom of the autoclave after membrane synthesis.
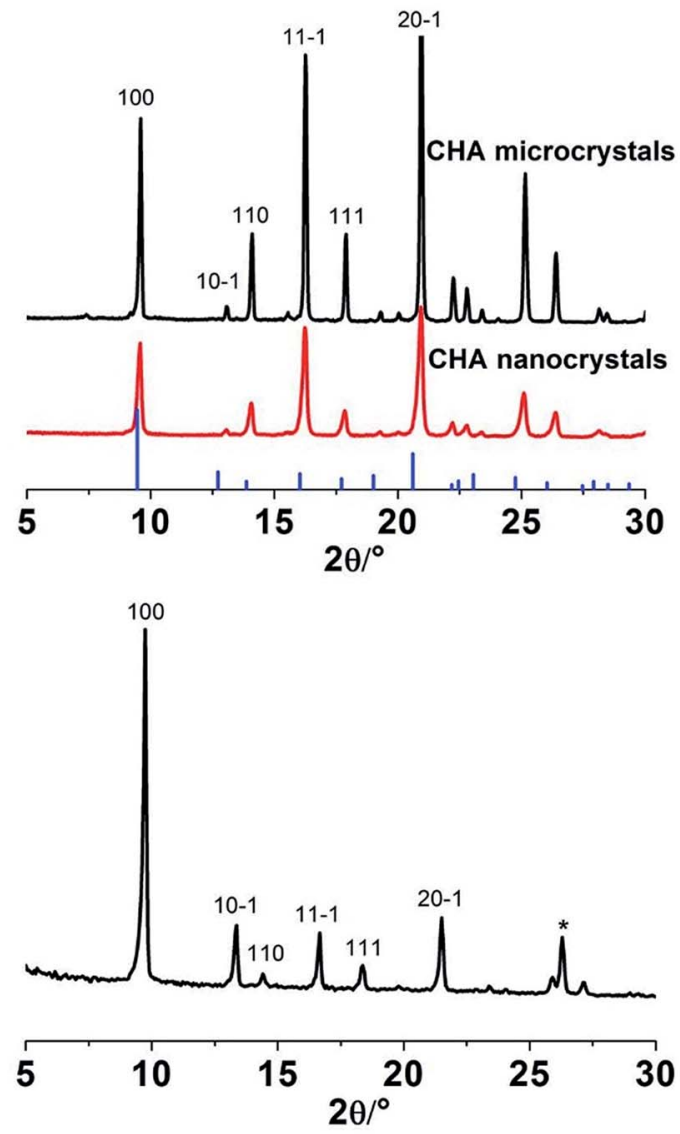

Fig. 2 The XRD patterns of the prepared Si-CHA powder (up) and a CHA membrane supported on an $\alpha$-alumina disc (down). The indexed reflections emanate from the $\mathrm{CHA}$ phase, while the reflection marked with an asterisk emanate from the alumina support.

crystals is ranging from $c a$. 20 to $200 \mathrm{~nm}$ and again, the crystals display a well-defined pseudocube habit.

XRD data confirm that the nanocrystals are comprised of pure CHA phase, see Fig. 2. The lower intensities and broader reflections are a result of broadening due to small crystal size. The SEM image in Fig. 1c illustrates that CHA microcrystals with a size of $c a .3 \mu \mathrm{m}$ also formed in the autoclave during membrane synthesis. The recovered CHA microcrystals could also be used for preparation of CHA nanocrystals, implying that our method offers a green synthesis route.

Fig. 3a shows a SEM image of the support seeded with SiCHA nanocrystals. As the rounded alumina grains are barely visible, it can be concluded that the seed layer is a quite dense monolayer of CHA crystals. The XRD pattern of an assynthesised CHA membrane (Fig. 2) shows that the film comprises only the CHA phase, i.e. with no presence of other zeolite or amorphous phases. The strong diffraction peak at $2 \theta=9.6^{\circ}$ shows that the CHA crystals in the film are weakly (100) oriented, which is in line with previous reports for other Si-CHA membranes. ${ }^{23}$ Consequently, crystals are preferentially oriented with pores running in the $\langle 100\rangle$ family of directions across the membrane, i.e. perpendicular to the membrane surface. 

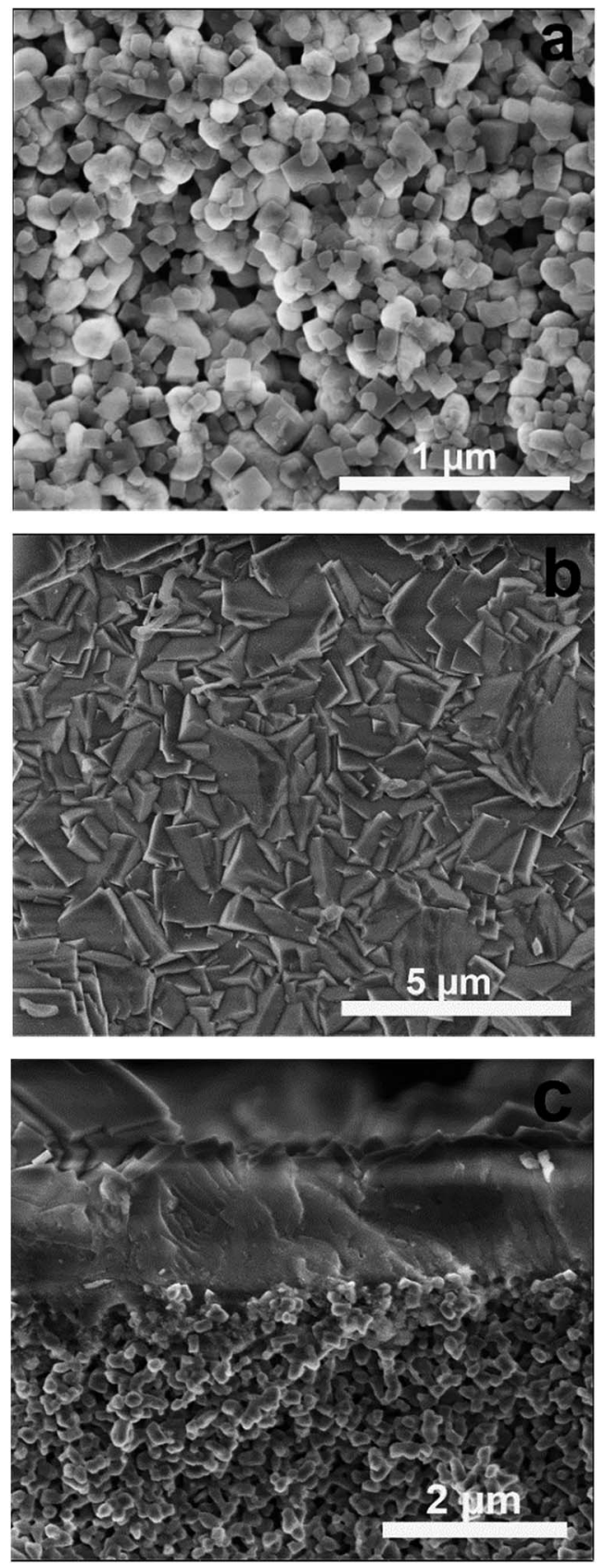

Fig. 3 SEM images of the Si-CHA seed layer on the support (a), topview (b) and cross-section (c) of a calcined CHA membrane.

Non-calcined as-synthesised CHA membranes contain TMAda $^{+}$template molecules blocking the zeolite pores. Accordingly, defect-free membranes are impermeable before removing the template by calcination. To evaluate the quality of the as-synthesised membranes, the single gas helium permeance was measured at $293 \mathrm{~K}$ and 5 bar feed pressure and atmospheric permeate pressure for 9 membranes. The helium permeance was very low in the range 0.5 to $6 \times 10^{-9} \mathrm{~mol} \mathrm{~m}^{-2} \mathrm{~s}^{-1} \mathrm{~Pa}^{-1}$ indicating that the membranes are essentially free from defects before calcination. After calcination, the morphology of the membranes was characterised by SEM. Top-view SEM images (see Fig. 3b) show that the film is continuous and comprised of well- intergrown zeolite crystals. No defects such as pinholes or cracks in the membrane could be observed. The cross-sectional SEM image show that the film appears to be rather even with a total thickness of about $1.3 \mu \mathrm{m}$ (see Fig. 3c). Moreover, the support was open and clean, no invasion could be observed.

Table 1 shows single gas permeances before and after calcination for four membranes prepared in the same batch. Very low helium permeances, in average $2.8 \times 10^{-9} \mathrm{~mol} \mathrm{~m}^{-2} \mathrm{~s}^{-1} \mathrm{~Pa}^{-1}$, were observed before calcination, i.e. the membranes are essentially defect-free before removing template. After calcination, the average single gas helium permeance increases to about $34 \times 10^{-7} \mathrm{~mol} \mathrm{~m}^{-2} \mathrm{~s}^{-1} \mathrm{~Pa}^{-1}$. Meanwhile, the average $\mathrm{CO}_{2}$ single gas permeance was as high as $122 \times 10^{-7} \mathrm{~mol} \mathrm{~m}^{-2} \mathrm{~s}^{-1}$ $\mathrm{Pa}^{-1}$ at 1.8 bar (absolute) feed pressure and 1 bar (absolute) permeate pressure at room temperature. A previously reported SSZ-13 membrane displayed a single gas $\mathrm{CO}_{2}$ permeance of approximately $3 \times 10^{-7} \mathrm{~mol} \mathrm{~m}^{-2} \mathrm{~s}^{-1} \mathrm{~Pa}^{-1}$ at room temperature and 6 bar feed pressure and atmospheric pressure on permeate side. ${ }^{16}$ The very high permeance of the CHA membranes reported in the present work is a result of the graded support with low flow resistance and the thin zeolite film layer grown on a support without invasion as well as the low pressure difference ( $\Delta P=0.8$ bar) for the measurement, and also of the drying procedure. As reported for polymeric membranes, the drying process may have a significant effect on the separation performance. ${ }^{24-26}$ For zeolite membranes, adsorption of e.g. water from the ambient in the zeolite pores may reduce the $\mathrm{CO}_{2}$ permeance. For non-dried membranes, about $50 \%$ lower $\mathrm{CO}_{2}$ permeance was observed with similar separation factor, during mixture separation.

Fig. 4 shows the $\mathrm{CO}_{2}$ single gas permeance and flux as well as $\mathrm{CO}_{2} / \mathrm{CH}_{4}$ ideal selectivity as a function of $\Delta P$ at atmospheric permeate pressure and room temperature for membrane M1. The highest observed $\mathrm{CO}_{2}$ single gas permeance was $172 \times$ $10^{-7} \mathrm{~mol} \mathrm{~m}^{-2} \mathrm{~s}^{-1} \mathrm{~Pa}^{-1}$ at the lowest investigated $\Delta P$ of 0.5 bar. As $\Delta P$ increase, i.e. the feed pressure increased, the permeance reduced somewhat, which indicates that the adsorbed concentration of $\mathrm{CO}_{2}$ is not increasing proportionally to the feed pressure increase and also that the pressure drop over the support is increasing with increasing feed pressure and $\Delta P$. As the single gas $\mathrm{CH}_{4}$ permeance was very low and almost constant (not shown), the ideal selectivity follows the same trend as the

Table 1 The single gas permeation of the $\mathrm{CHA}$ membranes prepare from the same batch (test conditions: 1.8 bar (absolute) feed pressure and 1 bar (absolute) permeate pressure)

\begin{tabular}{lllll}
\hline & \multicolumn{2}{l}{ Permeance, $10^{-7} \mathrm{~mol} \mathrm{~m}^{-2} \mathrm{~s}^{-1} \mathrm{~Pa}^{-1}$} & \\
\cline { 2 - 3 } Membranes & Be & Before calcination & After calcination & After calcination \\
\cline { 2 - 3 } M1 & 0.015 & 32 & 126 \\
M2 & 0.013 & 31 & 118 \\
M3 & 0.027 & 35 & 121 \\
M4 & 0.058 & 37 & 122 \\
Average & 0.028 & 34 & 122
\end{tabular}



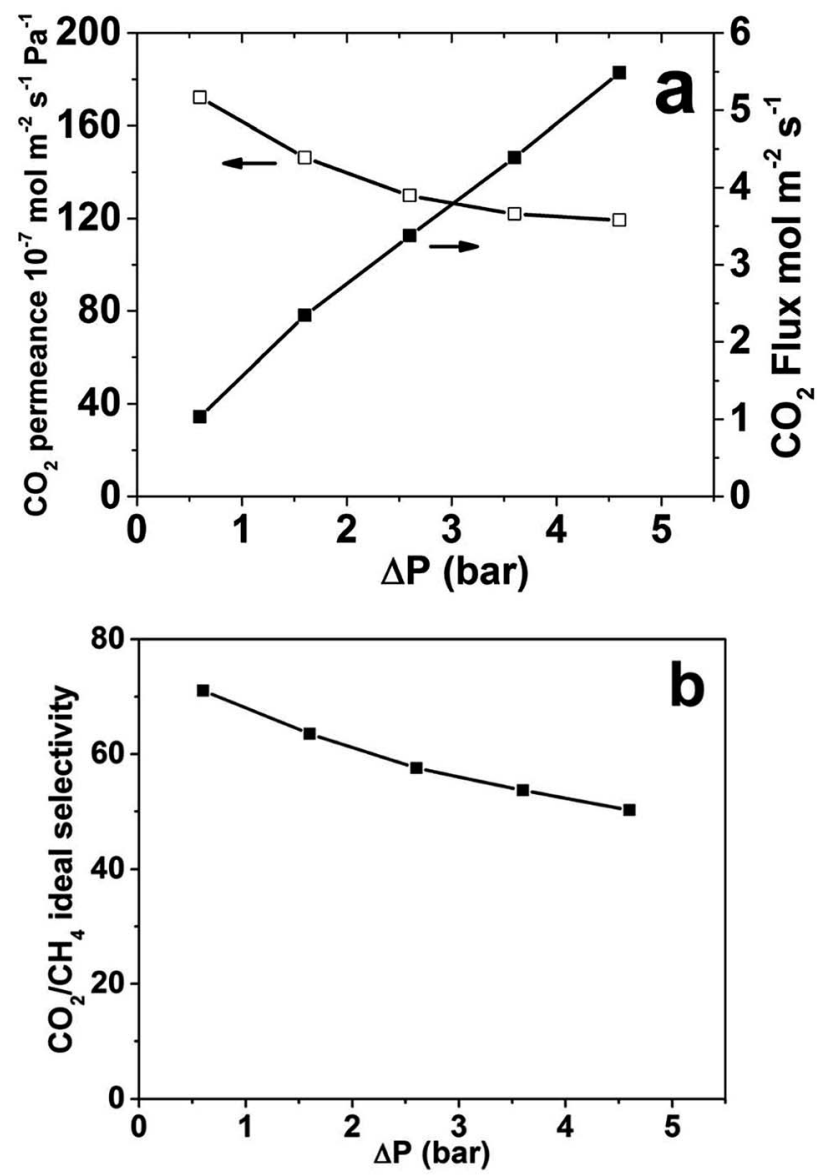

Fig. 4 (a) $\mathrm{CO}_{2}$ single gas permeance and flux, (b) $\mathrm{CO}_{2} / \mathrm{CH}_{4}$ ideal selectivity as a function of $\Delta P$, i.e. the pressure difference between the feed side and permeate side, moreover the absolute pressure on the permeate side was kept at 1 bar.

single gas $\mathrm{CO}_{2}$ permeance and is decreasing with increasing $\Delta P$. The $\mathrm{CO}_{2}$ flux increases with increasing $\Delta P$. The highest $\mathrm{CO}_{2}$ flux was $5.5 \mathrm{~mol} \mathrm{~m}^{-2} \mathrm{~s}^{-1}$ at a $\Delta P$ of 4.5 bar. However, the flux did not increase proportionally to $\Delta P$; as $\Delta P$ increased from 0.5 to $4.5 \mathrm{bar}$, nine times, the flux only increased from 1.03 to $5.49 \mathrm{~mol} \mathrm{~m}^{-2} \mathrm{~s}^{-1}$, only around five times. Again, this can be ascribed to that the adsorbed concentration of $\mathrm{CO}_{2}$ is not increasing proportionally to the feed pressure increase and also that the pressure drop over the support is increasing with increasing feed pressure and $\Delta P$.

The average separation selectivity for equimolar $\mathrm{CO}_{2} / \mathrm{CH}_{4}$ gas mixture for four CHA membranes prepared using the same method but in 4 batches was 25 with a standard deviation of 8 at room temperature. The best membrane was further investigated and all other data was recorded for this membrane. Fig. 5 illustrates the measured membrane separation selectivity and permeance as a function of temperature with experimental error indicated at $293 \mathrm{~K}$. The membranes were $\mathrm{CO}_{2}$-selective in the entire studied temperature range. The separation selectivity increased with decreasing temperature most likely due to both increased $\mathrm{CO}_{2} / \mathrm{CH}_{4}$ adsorption selectivity and increased blocking of defects by capillary condensation of $\mathrm{CO}_{2}$ at lower
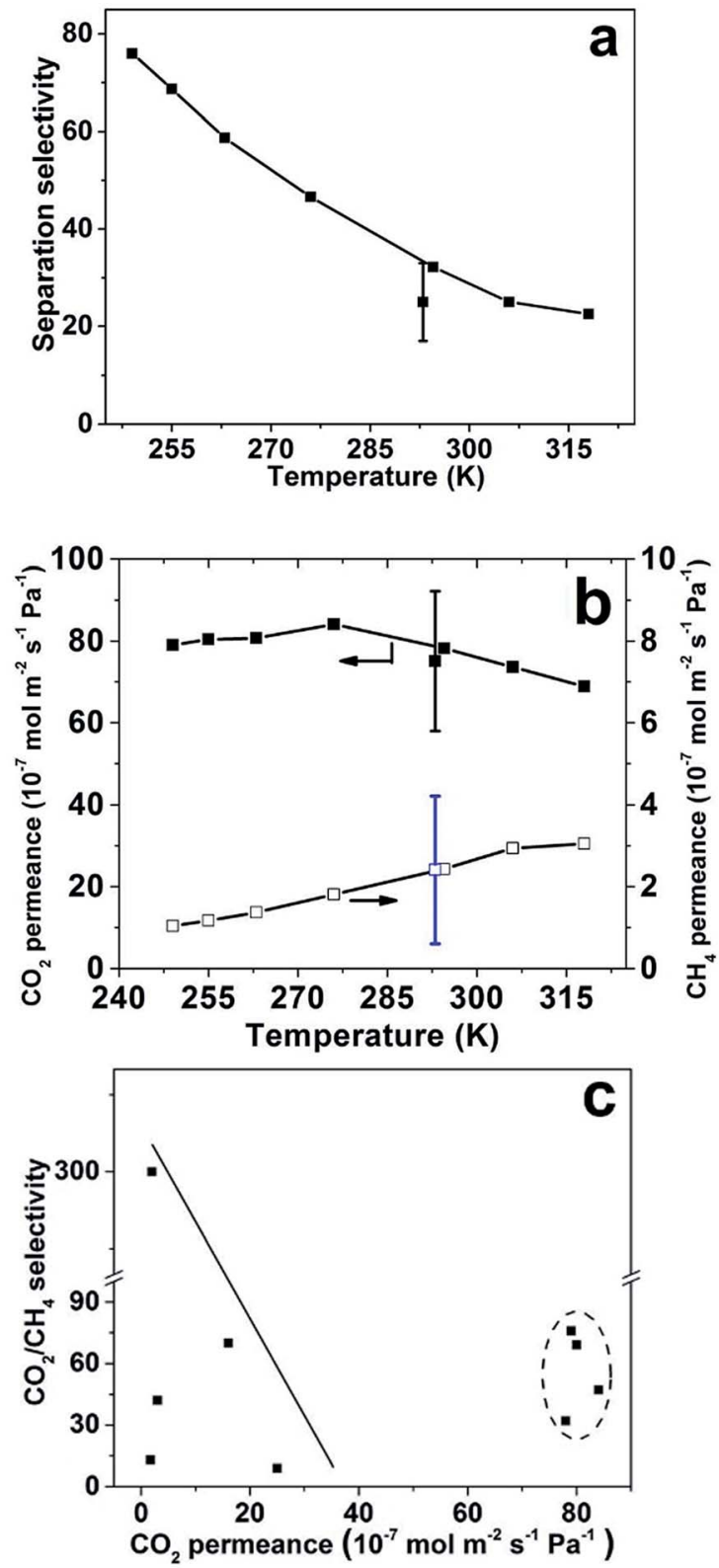

Fig. 5 Equimolar $\mathrm{CO}_{2} / \mathrm{CH}_{4}$ gas mixture separation results at feed pressure of 9 bar and permeate pressure of 1 bar, (a) $\mathrm{CO}_{2} / \mathrm{CH}_{4}$ separation selectivity as a function of temperature; (b) $\mathrm{CO}_{2}$ and $\mathrm{CH}_{4}$ permeances as a function of temperature and (c) comparison with data from SSZ-13 and SAPO-34 membranes reported by other groups. ${ }^{9,16,18,27,28}$ Data within the dotted oval are results from the present work. The points with error bars indicate the average and standard deviation for four membranes prepared using the same method but in 4 batches measured at room temperature and the best membrane was selected for the measurement at different temperatures.

temperatures. The same trend was observed for the separation factor (see Table 2). At room temperature, a $\mathrm{CO}_{2} / \mathrm{CH}_{4}$ separation selectivity of 32 was observed, with a corresponding separation factor of 26. Starting from the highest temperature (318 K), the selectivity increased with decreasing temperature, and the highest observed separation selectivity was 76 , with 
Table $2 \mathrm{CO}_{2}$ flux, permeate concentration and $\mathrm{CO}_{2} / \mathrm{CH}_{4}$ separation factors observed at various temperatures for the best membrane. Average and standard deviation for four membranes prepared using the same method but in 4 batches measured at $293 \mathrm{~K}$ given within brackets

\begin{tabular}{|c|c|c|c|c|}
\hline$T(\mathrm{~K})$ & $\mathrm{CO}_{2}$ flux $\left(\mathrm{mol} \mathrm{m}{ }^{-2} \mathrm{~s}^{-1}\right)$ & $\mathrm{CO}_{2}$ & $\mathrm{CH}_{4}$ & $\begin{array}{l}\mathrm{CO}_{2} / \mathrm{CH}_{4} \text { membrane } \\
\text { separation factor }\end{array}$ \\
\hline 306 & 2.61 & 95.23 & 4.77 & 20 \\
\hline 295 & $2.77(2.67 \pm 0.6)^{a}$ & 96.23 & 3.77 & $26(20 \pm 6)^{a}$ \\
\hline 276 & 2.97 & 97.35 & 2.65 & 37 \\
\hline 249 & 2.78 & 98.35 & 1.65 & 60 \\
\hline
\end{tabular}

${ }^{a}$ Average and standard deviation at about $293 \mathrm{~K}$ measured for four CHA membranes prepared using the same method but in 4 batches.

a corresponding separation factor of 60 , at the lowest temperature studied $(249 \mathrm{~K})$.

Fig. $5 \mathrm{~b}$ shows that the $\mathrm{CO}_{2}$ permeance was very high in the studied temperature range, and passed through a maximum value at $276 \mathrm{~K}$. The highest observed $\mathrm{CO}_{2}$ permeance during mixture separation was $84 \times 10^{-7} \mathrm{~mol} \mathrm{~m}^{-2} \mathrm{~s}^{-1} \mathrm{~Pa}^{-1}$ with a $\mathrm{CO}_{2} / \mathrm{CH}_{4}$ separation selectivity of 47 at the same temperature. The mixture $\mathrm{CO}_{2}$ permeance was also as high as $78 \times$ $10^{-7} \mathrm{~mol} \mathrm{~m}^{-2} \mathrm{~s}^{-1} \mathrm{~Pa}^{-1}$ at room temperature. To the best of our knowledge, these $\mathrm{CO}_{2}$ permeances are the highest reported for CHA membranes at the similar conditions. However, this permeance is much lower than the single gas permeance of $122 \times$ $10^{-7} \mathrm{~mol} \mathrm{~m}^{-2} \mathrm{~s}^{-1} \mathrm{~Pa}^{-1}$, measured at comparable conditions, at a feed pressure of 4.5 bar during single gas permeation, i.e. the same as the partial pressure of $\mathrm{CO}_{2}$ of $4.5 \mathrm{bar}$ on feed side during mixture separation. This is likely due to the influence of $\mathrm{CH}_{4}$ on the transport of $\mathrm{CO}_{2}$ through the membrane by competitive adsorption with $\mathrm{CO}_{2}$. Fig. $5 \mathrm{c}$ summarizes the best $\mathrm{CO}_{2} / \mathrm{CH}_{4}$ separation data reported for CHA membrane in the literature ${ }^{9,16,18,27,28}$ and the separation data obtained in the present work. Obviously, the membranes reported in the present work display very high permeance, while the separation selectivity is comparable to previous reports for the best SSZ-13 and SAPO-34 zeolite membranes, ${ }^{18,27}$ but lower than Zhou et al., that reported a SSZ-13 membrane with a selectivity of $300 .{ }^{29}$ The observed $\mathrm{CO}_{2}$ permeances for the CHA membranes in the present work are comparable with our previous reported high-flux MFI membrane, but with 8 times higher separation factor at similar test conditions. ${ }^{6}$ In addition, polymeric membranes usually show comparable selectivities of $10-100$ for $\mathrm{CO}_{2} / \mathrm{CH}_{4}$ separation, however the $\mathrm{CO}_{2}$ permeances are normally lower than $1000 \mathrm{GPU}$, i.e. lower than $3.35 \times 10^{-7} \mathrm{~mol} \mathrm{~m}^{-2} \mathrm{~s}^{-1} \mathrm{~Pa}^{-1}$. 30

Table 2 shows the $\mathrm{CO}_{2}$ fluxes, the concentration of $\mathrm{CO}_{2}$ and $\mathrm{CH}_{4}$ in the permeate stream and the $\mathrm{CO}_{2} / \mathrm{CH}_{4}$ separation factor with average and standard deviation at room temperature for four CHA membranes prepared using the same method but in 4 batches. The latter term denotes the ratio of $\mathrm{CO}_{2}$ and $\mathrm{CH}_{4}$ concentration in the permeate stream over the same ratio in the feed. In the entire temperature range, the observed $\mathrm{CO}_{2}$ flux was very high, i.e. $2.45-2.97 \mathrm{~mol} \mathrm{~m}^{-2} \mathrm{~s}^{-1}$, corresponding to $388-470$ $\mathrm{kg} \mathrm{m}{ }^{-2} \mathrm{~h}^{-1}$ although the partial pressure difference of $\mathrm{CO}_{2}$ across the membrane was relatively low at about $350 \mathrm{kPa}$. At room temperature, the average separation factor was 20 with a standard deviation of 6 for four CHA membranes and the best separation factor was 26 with a $\mathrm{CO}_{2}$ flux of $2.77 \mathrm{~mol} \mathrm{~m}^{-2} \mathrm{~s}^{-1}$ $\left(438 \mathrm{~kg} \mathrm{~m}^{-2} \mathrm{~h}^{-1}\right)$, which was significantly higher than that for our MFI membranes with a separation factor of 3.5 and a flux of $300 \mathrm{~kg} \mathrm{~m}^{-2} \mathrm{~h}^{-1}$. ${ }^{6}$ It was also more than 175 times higher than that $\left(2.5 \mathrm{~kg} \mathrm{~m}^{-2} \mathrm{~h}^{-1}\right)$ reported for the highly $\mathrm{CO}_{2}$-selective SAPO34 zeolite membranes at similar experimental conditions. ${ }^{9}$

\section{Conclusions}

In the present work, high-flux CHA membranes with a thickness of $c a .1 .3 \mu \mathrm{m}$ were synthesized from Si-CHA nanocrystals with much smaller size (20-200 $\mathrm{nm}$ ) than previously reported using fluoride as mineralizing agent for the first time. The membranes displayed a very high performance for separation of equimolar $\mathrm{CO}_{2} / \mathrm{CH}_{4}$ mixtures with the highest observed $\mathrm{CO}_{2}$ mixture permeance of $84 \times 10^{-7} \mathrm{~mol} \mathrm{~m}^{-2} \mathrm{~s}^{-1} \mathrm{~Pa}^{-1}$ and a separation selectivity of 47 at 9 bar feed pressure, atmospheric permeate pressure and $276 \mathrm{~K}$. The separation selectivity was comparable with that reported for other high-flux CHA membranes, nevertheless with much higher $\mathrm{CO}_{2}$ permeance and flux to that reported previously at comparable test conditions.

\section{Conflicts of interest}

There are no conflicts to declare.

\section{Acknowledgements}

The Swedish Research Council for Environment, Agricultural Sciences and Spatial Planning Formas, the Swedish Energy Agency and Bio4Energy are gratefully acknowledged for financial support.

\section{Notes and references}

1 R. W. Baker and K. Lokhandwala, Ind. Eng. Chem. Res., 2008, 47, 2109-2121. 
2 X. Y. Chen, H. Vinh-Thang, A. A. Ramirez, D. Rodrigue and S. Kaliaguine, $R S C A d v$., 2015, 5, 24399-24448.

3 S. Basu, A. L. Khan, A. Cano-Odena, C. Liu and I. F. J. Vankelecom, Chem. Soc. Rev., 2010, 39, 750-768.

4 N. Kosinov, J. Gascon, F. Kapteijn and E. J. M. Hensen, J. Membr. Sci., 2016, 499, 65-79.

5 D. Korelskiy, P. Ye, S. Fouladvand, S. Karimi, E. Sjöberg and J. Hedlund, J. Mater. Chem. A, 2015, 3, 12500-12506.

6 L. Sandström, E. Sjöberg and J. Hedlund, J. Membr. Sci., 2011, 380, 232-240.

7 Y. Cui, H. Kita and K.-I. Okamoto, J. Mater. Chem., 2004, 14, 924.

8 J. van der Bergh, W. Zhu, J. Gascon, J. A. Moulijn and F. Kapteijn, J. Membr. Sci., 2008, 316, 35.

9 S. Li, J. L. Falconer and R. D. Noble, Microporous Mesoporous Mater., 2008, 110, 310-317.

10 M. L. Carreon, S. Li and M. A. Carreon, Chem. Commun., 2012, 48, 2310-2312.

11 N. Hedin, G. J. DeMartin, W. J. Roth, K. G. Strohmaier and S. C. Reyes, Microporous Mesoporous Mater., 2008, 109, 327334.

12 H. Maghsoudi, M. Soltanieh, H. Bozorgzadeh and A. Mohamadalizadeh, Adsorption, 2013, 19, 1045-1053.

13 R. Krishna and J. M. van Baten, J. Membr. Sci., 2010, 360, 323-333.

14 S. I. Zones, Zeolite SSZ-13 and its method of preparation, US Pat., 4544538, 1985.

15 N. Kosinov, C. Auffret, G. J. Borghuis, V. G. P. Sripathi and E. J. M. Hensen, J. Membr. Sci., 2015, 484, 40-145.

16 H. Kalipcilar, T. C. Bowen, R. D. Noble and J. L. Falconer, Chem. Mater., 2002, 14, 3458-3464.
17 Y. Zheng, N. Hu, H. Wang, N. Bu, F. Zhang and R. Zhou, J. Membr. Sci., 2015, 475, 303-310.

18 N. Kosinov, C. Auffret, C. Gücüyener, B. M. Szyja, J. Gascon, F. Kapteijn and E. J. M. Hensen, J. Mater. Chem. A, 2014, 2, 13083.

19 M. J. Díaz-Cabanas, P. A. Barrett and M. A. Camblor, Chem. Commun., 1998, 1881-1882.

20 X. Zhu, N. Kosinov, J. P. Hofmann, B. Mezari, Q. Qian, R. Rohling, B. M. Weckhuysen, J. Ruiz-Martínezb and E. J. M. Hensen, Chem. Commun., 2016, 52, 3227-3230.

$21 \mathrm{~J}$. Hedlund, A. Holmgren and L. Yu, Methods for preparing supported zeolite films, GB patent application, GB1714269.6, Sep 2017.

22 M. M. J. Treacy and J. B. Higgins, Collection of simulated XRD powder patterns for zeolites, Elsevier, 5th revised edn, 2007.

23 M. Calligaris, G. Nardin and L. Randaccio, Zeolites, 1983, 3, 205-208.

24 J. Albo, J. Wang and T. Tsuru, J. Membr. Sci., 2014, 453, 384393.

25 J. Albo, J. Wang and T. Tsuru, J. Membr. Sci., 2014, 449, 109118.

$26 \mathrm{~J}$. Albo, H. Hagiwara, H. Yanagishita, K. Ito and T. Tsuru, Ind. Eng. Chem. Res., 2014, 53, 1442-1451.

27 E. Kim, W. Cai, H. Baik and J. Choi, Angew. Chem., Int. Ed., 2013, 52, 5280-5284.

28 Y. Tian, L. Fan, Z. Wang, S. Qui and G. Zhu, J. Mater. Chem., 2009, 19, 7698.

29 R. Zhou, E. W. Ping, H. H. Funke, J. L. Falconer and R. D. Noble, J. Membr. Sci., 2013, 444, 384.

30 H. Lin and M. Yavari, J. Membr. Sci., 2015, 475, 101-109. 